\title{
The social and environmental dimensions of nutrition science
}

\author{
Massimo Pettoello-Mantovani * \\ Institute of Pediatrics, Centre for Pediatric Gastroenterology and Nutrition, \\ University of Foggia, Viale Pinto 1, I-71100 Foggia, Italy
}

\begin{abstract}
Objective: To emphasise the importance of defining a new nutrition science and food policy that includes social and environmental dimensions.

Design: Nutrition science and food policy is put in the context of sustainable development. Examples are presented to show that a number of factors including exploitation of resources, disrespect for land and food insecurity contribute to the decline of a culture. The fate of cultures that lack implemented sustainable development strategies is discussed.

Conclusion: Pressure from low-income and economically challenged countries combined with the efforts of not-for-profit private institutions is proposed. The goal is to produce and provide science-based evidence and guidelines to be used as a tool to encourage institutions and organisations to redefine their policies to deal effectively with global issues.
\end{abstract}

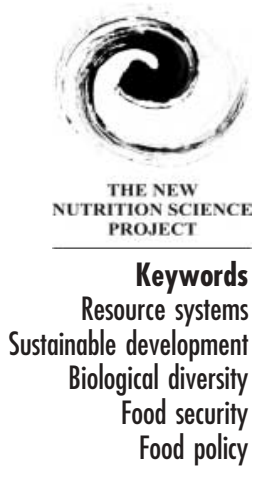

Present and potentially even greater dimensions of environmental degradation have their roots in rapid population growth typical in low-income countries and unsustainable consumption patterns typical in highincome countries, amongst other things. A conservative estimate of the global population projects 8 billion people on the planet by the year 2020 with most of this increase in the cities of low-income countries. World-wide, the urban population is expected to double from the current 2 billion people to 4 billion in 2025. Increases in income, greater urbanisation (which leads to a shift in diet from roots, tubers and lower-status grains to higher-prestige cereals, livestock and vegetables) and overall population growth could mean that the demand for food in 2025 will be more than double that of current levels of production.

A broad class of global threats increasingly afflicted the post World War II era, particularly as from the 1980s. Among them, the loss of biodiversity is an especially urgent threat, the consequences of which are irreversible ${ }^{1}$. The permanent loss of species means we will no longer have these organisms as sources of food, oils, medicines, fibres, chemicals and other commodities of importance to both low-income and high-income countries. Furthermore, in the modern world, diseases readily cross borders, and environmental degradation can have global consequences that threaten the populations of all nations. Great human suffering due to natural disasters, outbreaks of new or re-emerging infectious diseases and the increasing social burden of chronic diseases, as well as a broad range of other environmental, economic or social and political factors, calls for economic development that can be sustained for growing populations and respond to threats to human health and the environment ${ }^{2,3}$.

Continued population growth and environmental pressures could lead to immense social unrest and make the world substantially more vulnerable to serious international frictions and global instability. Advances in science and technology alone will not be sufficient both to resolve the gigantic problems of preserving natural and human resources and to provide answers related to global issues such as economic and political influence on food supply and adequate nutrition. A broader and comprehensive approach is needed ${ }^{4}$.

\section{Discussion}

\section{Integrated resource systems}

During history, humans have constantly manipulated natural resources to produce the food and other products they needed to sustain growing populations. Such harnessing and use of natural resources to meet the needs of humanity throughout the development of civilisation has resulted in marked, sometimes beneficial but often detrimental, alterations in natural resource systems throughout the world ${ }^{5}$.

Sustainable development focuses on what would enhance the quality of life; it does not define a particular path. A peculiarity of sustainable development is the capacity to adapt to constantly changing conditions, retaining the flexibility to work with uncertainty and with differences in local conditions and in public expectations shaped by culture, values and experience. 
The redefinition of nutrition science and food policy to meet the realities and challenges of the twenty-first century means thinking in terms of integrated systems. These will include aspects besides health, such as evolution, history, resources, the environment, biodiversity, agriculture, food traditions, technology and industry, equity and poverty, economics and politics, philosophy and ethics. These and more aspects are all interdependent, one with the others.

For sustainable development to reach its goals and to be effective it must be participatory, involving local communities and individuals to give substantive input into designing and implementing development programmes and projects. In fact, long-term sustainability of any development can be ensured only when local people have a sense of ownership and personal investment in their own development.

High-income and low-income countries are linked as never before in a world that is increasingly interdependent. Countries with large populations like China, India and Brazil are characterised by growing economic and demographic weight that is having a major impact on employment, trade, travel, immigration and other areas. The global marketplace weakens the lines between national economies; the communications revolution brings together cultures, knowledge and information. Health, environment and food, together with peace and security, are increasingly global issues that all countries must deal with. Hunger, poverty, disease and conflict have become not just humanitarian concerns, but shared problems as they trickle over borders and affect countries around the world ${ }^{6}$.

Efforts to pursue sustainable development take place within a context of shared interests, and articulated interlinkages and international development co-operation are increasingly viewed as necessary responses to these global challenges. The dimensions of sustainable development include the full range of economic, social, environmental and governance activities, and they too are interdependent and mutually reinforcing. For instance, no economic initiative that depletes the natural resources upon which it depends will last; no educational system will give children a place to be educated if they instead have to go to work to survive; to be sustainable, no agricultural production programme can afford to exclude women who are often the main food producers; and no country can lift itself out of poverty if it is struggling to pay back debts or end domestic wars or armed clashes.

Equitable sustainable development must be also environmentally sustainable and strengthen the economic, social, environmental and governance capacity of women and men, girls and boys. Such sustainable development is reached only if the economies of the world try to meet contemporary needs and contribute to the setting of an integrated resource system without compromising the resources available to future generations.

\section{Effective sustainable development}

The World Summit on Sustainable Development (WSSD) at Johannesburg in September 2002 renewed the global community's responsibility in many areas of sustainable development, including water and sanitation, agriculture and food supply, and in general sustainable production and consumption of food. All the international agreements reached in Johannesburg established a common foundation of values and reflected an unprecedented consensus on the goals, conditions and resources needed to achieve sustainable development. The WSSD has been a recent further important step towards awareness on areas strictly connected with developmental sustainability, such as nutrition science and food policy.

Humans live in a world that developed over billions of years expressing an enormous range of species, a complex and balanced ecosystem, and soil and groundwater accumulations that have taken millennia to build up. It took just 200 years to bring us to a preoccupation with problems that threaten the sustainability of production of food and other products of agriculture, fisheries and forestry ${ }^{7}$.

Attempts to define the new nutrition science and food policy lead to the importance of viewing such areas of interest: not isolated but more and more integrated in an interdependent system. Such a system should involve several dimensions including, besides resources, evolution, history, ecology, environment, biodiversity, agriculture, traditional elaboration of food, technology, industry, health, equity, economics, politics, philosophy and ethics. How much these dimensions are interdependent and inevitable is immediately clear by approaching the issue of the new nutrition science and food policy from any one of the dimensions indicated ${ }^{8,9}$.

For instance, by examining nutrition science and food policy as part of a progressively more integrated resource system, the role of biodiversity and how much it matters to the economy are immediately evident. It is a fact that human existence depends on biological diversity, which has, however, for a long time been neglected in economics. Most economists, until recently, viewed it as part of recreation, and sustainable use of natural resources 
is still widely considered as a luxury, reserved for highincome countries ${ }^{10}$. The fast expanding field of biodiversity economics constitutes one key element towards sustainability. So far it has shown, in economic terms, that biological diversity contributes to ecosystem productivity, provides a cover against environmental variability and environmental disasters, and delivers a multitude of valuable ecosystem services. It has been further demonstrated that the loss of biological diversity is reflected neither in market prices nor in government policies, and is thus ignored by resource users. Market and policy failures are considered as the main underlying causes of biodiversity loss. Economists interested in biodiversity are increasingly focusing their efforts on formulating ways to value natural resources and the ecosystem services they provide $^{11,12}$.

It is thus quite evident that as in a domino effect, by approaching the concept of the new nutrition science and food policy from one of the dimensions, we are forced to take into account and integrate factors from each one of the dimensions identified.

\section{A global integrated living resource system}

Any analysis on how to manage and correctly balance integrated physical, living and human global resource systems and sustainable development sooner or later reveals our responsibility. In fact, the definition sustainable development has an interesting development itself.

The term sustainable harvesting was introduced in the seventeenth century by forestry experts in Germany to call attention to the fact that only the number of trees should be harvested that would grow in a given time. Today it means simply that the present generation has an obligation not to use resources in ways that would impair the lives of its descendants. That is the responsibility we all have, because one obvious way to save resources is to slow the industrialisation of low-income countries. Another is to reduce the current consumption levels of high-income countries.

The strategists of sustainable development incorporated economic growth in the term, so that sustainable development also had to address improving education, health and nutrition. It had to include access for lowincome countries' exports in high-income countries' markets. It had to mean aid to the low-income countries, both financial and technical ${ }^{13}$.

During the last 15 years the definition of sustainable development came to cover the whole agenda for worldwide social equity. This important concept was incorporated in the official documents of the 1992 United Nations' (UN) conference in Rio de Janeiro (UN Agenda 21) and later was confirmed and broadened at the Johannesburg WSSD in 2002. At the UN Conference on Financing for Development in Monterrey in 2002, world leaders established a new agreement for sustainable development. At the heart of this agreement is the understanding that low-income countries bear the primary responsibility for their own development while high-income countries have a duty to provide effective and predictable aid and to remove the inconsistencies in their broader policies that affect low-income countries. The principles of mutual accountability were agreed to at the G8 Summit, held in Kananaskis, Alberta, June 2002, which focused on Africa, resulting in the G8 Africa Action Plan.

Thus the redefinition and broadening of important concepts like sustainability of development and integrated resource systems is a process that has firmly been established; such concepts are subjected to a constant process of refinement and have become part of the global concern. However, it must be noted that the success of international conferences on such topics has been disappointing. Unfortunately, before any international conference on sustainable development and integrated resources there is the clear perception that significant cultural advancements will be made but concomitantly the question arises on how much the decision process will be capable of producing serious and sustained results.

The active participation in such meetings of motivated low-income countries, and the need to maintain a high consensus, results in pressure to produce documents over difficult issues but at the same time it creates a strong incentive, in particular, not to insist on rigorous procedures for verification and enforcement. Therefore, although awareness is progressively increasing, one obvious reality of world environmental politics is the deep suspicion among low-income or economically challenged countries that these agreements are merely devices to suppress their economic growth, engineered by the high-income countries to prevent the emergence of competitors. In repeated attempts to remove this suspicion, the high-income countries have made considerable promises to help the low-income countries in many ways. But with little in the way of enforcement, many of the promises have remained unfulfilled. That, in turn, has reinforced the suspicions of the low-income countries and their inclination not to co-operate ${ }^{14-16}$

We can conclude on this point that whereas on the one side we have a constant beneficial development of global ethical principles, on the other side we have a substantial lack of practical application of such moral definitions and directions. The clear impression is that there is always a significant gap of time between the constant redefinition of important issues and principles and the capability of national and international political organisations to elaborate such new concepts into books and declarations, and in getting from texts into practice. Furthermore, whenever a kind of action is promoted, new visions and dimensions are already elaborated and the institutional strategy becomes de facto out of date and inefficient. The frustrating feeling is that institutional action plans are always late to meet the theory in time for solving global demands; as in Xeno's paradox where the powerful 
Achilles never was able to catch up with the defenceless but clever turtle, simply because she is always a step ahead.

\section{How to make the new nutrition science work}

Defining new principles for an integrated resource system and sustainable development is unproductive without an effective implementation of strategic plans. In fact, the constant question before any international conference on sustainable development is whether the institutional organisations are capable of producing serious and sustainable results. The process of drafting and negotiating international environmental treaties has developed in a way that proceeds by consensus rather than by divisive up-or-down votes. The typical approach of large institutional organisations is based on a belief that it is better to agree on a loosely worded text and trust to governments' good intentions than to press for tight legal language that risks jeopardising the whole task.

Pointing out that the Emperor has no clothes might perhaps look naïve. But, whatever the cause for institutional inefficiency, the reality is that institutional organisations elaborate articulated action plans that are morally satisfactory and perhaps largely inclusive of recent (often not the most up-dated) views and concepts, but lack the necessary strength to be applied.

It is legitimate to ask whether it makes any sense and whether it is correct to propose important topics such as the new nutrition science and food policy in the presence of a system that is inefficient to implement the proposed recommendations.

From the science point of view, the answer is yes. The typical scientific approach to problems requires leaving aside any political constraint in analysing facts and proposing new views and solutions to questions. But it isn't enough for scientists to analyse problems. They must also search to offer solutions while recognising possible obstacles.

\section{Conclusion}

To break the vicious circle of political inability and sometimes covert unwillingness to implement effective plans, a reasonable, basic approach might be considered. That would be clearly to acknowledge the impotence shown by the international political establishment to respond promptly and effectively to the proposals generated by a cultural open process that continuously redefines concepts of global importance and social impact ${ }^{17}$. Only strong pressure by the low-income and economically challenged countries can prompt institutional organisations to redefine their role with regard to action. The preliminary goal is then forcing such organisations to reach the capability of designing and issuing, besides declarations, an effective decision process capable of producing serious and sustainable results and rigorous procedures for verification and enforcement.
How can such ambitious proposal be supported? A feasible option could be tightly combining the pressure from the low-income and economically challenged countries with the efforts of private not-for-profit, notcompromised beneficial institutions (foundations, science-oriented organisations, etc.).

The goal is to create ad hoc high-quality task forces with the aim of producing and providing indisputable science-based studies and guidelines: tools that could be used in forcing institutional organisations to redefine their own political and technical approach to global issues, including for instance nutrition science and food policy.

\section{References}

1 Wahlqvist ML, Specht RL. Food variety and biodiversity: eco nutrition. Asia Pacific Journal Clinical Nutrition 1998; 7: 314-9.

2 Stavins RN. Harnessing market forces to protect the environment. Environment 1989; 31: 28-35.

3 Sterner T. Policy Instruments for Environmental and Natural Resource Management. Washington, DC: Resources for the Future, Inc., 2003.

4 Stewart RB. Controlling environmental risks through economic incentives. Columbia Journal of Environmental Law 1988; 13: 153-69.

5 Cannon G. The Fate of Nations. London: Caroline Walker Trust, 2003.

6 Oates WP, Portney PR. The political economy of environmental policy. In: Maler K-G, Vincent J, eds. Handbook of Environmental Economics, Vol. 1. Amsterdam: Elsevier, 2003; 325-54.

7 Anderson FR. Environmental Improvement through Economic Incentives. Baltimore, MD: The Johns Hopkins University Press for Resources for the Future, Inc., 1977.

8 McNeely JA. Economics and Biological Diversity: Developing and Using Economic Incentives to Conserve Biological Resources. Gland, Switzerland: The World Conservation Union (IUCN), 1988.

9 Montgomery CA. Pricing biodiversity. Journal of Environmental Economics and Management 1999; 38: $1-19$.

10 Dasgupta P. Economic value of biodiversity, overview. In: Levin SA, ed. Encyclopedia of Biodiversity, Vol. 2. San Diego, CA: Academic Press, 2001; 291-303.

11 Tietenberg TH. Pricing the Planet: Economic Analysis for Sustainable Development. New York: Columbia University Press, 1996; 123-38.

12 Tietenberg TH. Economic instruments for environmental regulation. Oxford Review of Economic Policy 1990; 6: 17-33.

13 Nichols AL. Targeting Economic Incentives for Environmental Protection. Cambridge, MA: MIT Press, 1984.

14 Hall C, Cleveland J, Kaufman R. Energy and Resource Quality, the Ecology of the Economic Process. Denver, CO: University Press of Colorado, 1986.

15 Helm D. Economic Policy toward the Environment. Oxford, UK: Blackwell, 1991.

16 Krawinkel M. Pediatric care and the problems of nutritional deficiencies. In: Polak G, ed. Medicine and Health-Course Catalog 2005. Vienna: Going International Information Services, 2004.

17 Nestle M. Safe Food: Bacteria, Biotechnology, and Bioterrorism. Berkeley and Los Angeles, CA: University of California Press, 2003. 